\title{
KOMODITAS POTENSIAL TANAMAN PALAWIJA DI KABUPATEN BLORA PROVINSI JAWA TENGAH
}

\author{
POTENTIAL COMMODITY OF SECONDARY CROP \\ IN BLORA DISTRICT CENTRAL JAVA PROVINCE
}

\author{
Agus Yuniawan Isyanto*, Sudrajat, Muhamad Nurdin Yusuf, Ane Novianty, \\ Benidzar M. Andrie, Wulan Priantika, Nurlina Harli, Saepul Aziz \\ Fakultas Pertanian Universitas Galuh \\ Jl. RE Martadinata No. 150 Ciamis 46274 \\ *E-mail corresponding: gusyun69@gmail.com \\ (Diterima 25-07-2019; Disetujui 30-07-2019)
}

\begin{abstract}
ABSTRAK
Identifikasi komoditas potensi perlu dilakukan dalam rangka pembangunan ekonomi suatu wilayah. Penelitian ini dilaksanakan dengan tujuan untuk mengidentifikasi komoditas unggulan tanaman palawija di Kabupaten Blora Provinsi Jawa Tengah. Analisis data dilakukan dengan menggunakan metode Location Quotient (LQ). Hasil penelitian menunjukkan bahwa jagung merupakan komoditas basis untuk Kecamatan Randublatung, Kradenan, Sambong, Jiken, Bogorejo, Jepon, Banjarejo, dan Tunjungan serta Kota Blora. Kedelai merupakan komoditas basis untuk Kecamatan Jati, Kedungtuban, Japah dan Kunduran. Kacang tanah merupakan komoditas basis untuk Kecamatan Kedungtuban, Cepu, Japah dan Todanan. Kacang hijau merupakan komoditas basis untuk Kecamatan Jati, Cepu, Sambong, Japah, Ngawen dan Kunduran. Ubi jalar merupakan komoditas basis untuk Kecamatan Kradenan, Sambong, Tunjungan dan Ngawen, serta Kota Blora. Ubi kayu merupakan komoditas basis untuk Kecamatan Kradenan, Sambong, Jiken, Banjarejo, Japah dan Ngawen.
\end{abstract}

Kata kunci: Palawija, Komoditas, LQ

Identification of potential commodities needs to be done in the context of the economic development of a region. This research was carried out with the aim of identifying potential commodities of secondary crops in Blora District, Central Java Province. Data analysis was carried out using the Location Quotient (LQ) method. The results showed that corn was a base commodity for Randublatung, Kradenan, Sambong, Jiken, Bogorejo, Jepon, Banjarejo, and Tunjungan Subdistricts and Blora City. Soybean is a base commodity for Jati, Kedungtuban, Japah and Kunduran Subdistricts. Peanuts are the base commodity for Kedungtuban, Cepu, Japah and Todanan Subdistricts. Mung beans are a basic commodity for Jati, Cepu, Sambong, Japah, Ngawen and Kunduran Subdistricts. Sweet potato is a base commodity for Kradenan, Sambong, Tunjungan and Ngawen Subdistricts, and Blora City. Cassava is a commodity base for the Kradenan, Sambong, Jiken, Banjarejo, Japah and Ngawen Districts.

Keywords: Secondary crop, potential commodity, LQ

\section{PENDAHULUAN}

Pembangunan daerah dilakukan dengan mendayagunakan sumberdaya yang ada secara optimal (Mahdalena dkk, 2015) yang diawali dengan penentuan sektor-sektor yang diprioritaskan untuk pertumbuhan ekonomi (Amalia, 2012), yang diharapkan dapat menjadi faktor pendorong bagi sektor lain agar berkembang menjadi penggerak utama 
pembangunan (Baransano dkk, 2016). Setiap wilayah harus mampu mengetahui potensi yang dimilikinya (Khasanah, 2018).

Kegiatan perencanaan pembangunan untuk mengembangkan sektor ekonomi dimulai dengan melakukan identifikasi sektor unggulan atau potensial ekonomi daerah (Widodo, 2006 dalam Rizani, 2017; Basuki dan Mujiraharjo, 2017; Raqib dan Rofiuddin, 2018).

Kebijakan utama yang perlu dilakukan dalam pembangunan daerah adalah mengusahakan semaksimal mungkin agar prioritas pembangunan daerah sesuai dengan potensi yang dimiliki oleh daerah (Sapriadi dan Hasbiullah, 2015; Kharisma dan Hadiyanto, 2017). Setiap wilayah memiliki keunggulan tertentu karena kekhasan wilayahnya (Astasari dkk, 2018; Isyanto dkk, 2018).

Peningkatan kesejahteraan masyarakat, salah satunya dapat dicapai dengan pertumbuhan ekonomi yang dapat meningkat jika ada satu atau beberapa sektor ekonomi unggulan (Massiseng dan Ummung, 2018). Agar pembangunan daerah lebih terfokus, salah satu upaya yang dapat dilakukan adalah mendeteksi sektor unggulan daerah (Basuki dan
Mujiraharjo, 2017) yang mempunyai peran yang sangat sentral, yaitu selain sebagai sektor yang efektif; juga menjadi motor penggerak dalam mengembangkan sektor sektor yang lainnya (Soleh dan Maryoni, 2017).

Komoditas unggulan memiliki posisi strategis untuk dikembangkan di suatu wilayah yang penetapannya didasarkan pada berbagai pertimbangan. Baik secara teknis (kondisi tanah dan iklim) maupun sosial ekonomi dan kelembagaan (penguasaan teknologi, kemampuan sumberdaya, manusia, infrastruktur, dan kondisi sosial budaya setempat) (Badan Penelitian dan Pengembangan Pertanian, 2005 dalam Sihombing, 2018).

Pengidentifikasian subsektor pertanian unggulan akan mempermudah dalam menentukan komoditas yang dikembangkan. Hal ini memerlukan analisis pada tiap subsektor di masing-masing wilayah sehingga pengembangan komoditi pada tiap wilayah dapat berjalan baik (Drianti dan Ardiyanto, 2016). Salah satu strategi yang bisa dilakukan adalah dengan penentuan komoditas unggulan, untuk kemudian dapat fokus pengembangan pada komoditas unggulan tersebut. Komoditas unggulan adalah suatu jenis komoditas yang paling diminati dan 
memiliki nilai jual tinggi serta diharapkan mampu memberikan pemasukan yang besar dibandingkan dengan jenis yang lainnya (Ridwan dkk, 2018).

Sektor pertanian merupakan sektor unggulan dalam pembangunan ekonomi di setiap daerah (Kurniawan, 2016). Peranan sektor pertanian di suatu daerah tidak lepas dari keberadaan komoditas unggulan pertanian (Hidayat dkk, 2014). Sentuhan kebijakan bagi pengembangan pembangunan pertanian wilayah masih sangat diperlukan untuk meningkatkan kesejahteraan masyarakat petani (Hidayat, 2013).

Kabupaten Blora masih didominasi oleh dua sektor utama, yaitu sektor pertambangan dan penggalian dan sektor pertanian dengan besar sumbangan terhadap PDRB masing-masing sebesar 24,12 persen dan 23,33 persen (BPS Kabupaten Blora, 2018a).

Saat ini ada banyak pendekatan yang digunakan untuk mengidentifikasi sektor potensial dari suatu wilayah tertentu. Namun, sebagian besar pendekatan ini cenderung hanya mengklasifikasikan sektor potensial ke dalam kelompok tertentu, misalnya, metode Location Quotient (LQ) (Munandar et al, 2017). Teknik LQ merupakan salah satu pendekatan yang umum digunakan dalam model ekonomi basis sebagai langkah awal untuk memahami sektor kegiatan yang menjadi pemicu pertumbuhan. LQ mengukur konsentrasi relatif atau derajat spesialisasi kegiatan ekonomi melalui pendekatan perbandingan (Jumiyanti, 2018).

LQ merupakan perbandingan relatif antara kemampuan sektor yang sama pada daerah yang lebih luas dalam suatu wilayah (Bafadal, 2014). LQ merupakan suatu alat analisis yang dapat digunakan dengan mudah, cepat dan tepat yang dapat di gunakan berulang kali dengan menggunakan berbagai perubah acuan dan periode waktu (Mangilaleng dkk, 2015).

Metode LQ merupakan salah satu pendekatan model ekonomi basis, relevan dan dapat digunakan sebagai salah satu teknik untuk mengidentifikasi penyebaran komoditas pertanian. Komoditas yang memiliki LQ $>1$ dianggap memiliki keunggulan komparatif karena tergolong basis. Komoditas yang tergolong basis dan memiliki wilayah sebaran yang paling luas menjadi salah satu indikator komoditas unggulan nasional (Hendayana, 2003 dalam Syafruddin dkk, 2018). 
Berdasarkan uraian di atas, maka tujuan penelitian ini adalah untuk mengidentifikasi komoditas potensial tanaman palawija di Kabupaten Blora Provinsi Jawa Tengah.

\section{METODE PENELITIAN}

Data yang digunakan dalam penelitian ini berupa data sekunder publikasi dari Badan Statistik Kabupaten Blora. Data yang diperoleh dianalisis dengan menggunakan analisis Location Quotient (LQ). Analisis ini merupakan suatu pendekatan yang dipergunakan untuk menentukan sektor basis atau non basis wilayah. Rumus Location Quotient (Bendavid-Val, 1991) sebagai berikut:

Dimana:

$$
L Q=\frac{X_{r} / R V_{r}}{X_{n} / R V_{n}}
$$

$$
\begin{aligned}
\mathrm{LQ}= & \text { Indeks pemusatan aktivitas } \\
& \text { ekonomi } \\
\mathrm{Xr}= & \text { Jumlah produksi pertanian } \\
& \text { komoditas tertentu di wilayah } \\
& \text { kecamatan } \\
\mathrm{Xn}= & \text { Jumlah produksi pertanian } \\
& \text { komoditas tertentu di wilayah } \\
& \text { kabupaten } \\
& \text { Total produksi sektor pertanian } \\
\mathrm{RVr}= & \text { di wilayah kecamatan }
\end{aligned}
$$

Suatu aktivitas dikatakan sebagai sektor basis ataupun non basis wilayah jika:

$$
\begin{gathered}
\mathrm{LQ}>1 \text {, merupakan aktivitas basis } \\
\mathrm{LQ}=1 \text {, aktivitas tersebut sama dengan } \\
\text { produksi keseluruhan }
\end{gathered}
$$

LQ $<1$, merupakan aktivitas non basis

\section{HASIL DAN PEMBAHASAN}

\section{Kondisi Umum Wilayah}

Kabupaten Blora secara geografis terletak di antara 1110 16' sampai 1110 338' Bujur Timur dan diantara 60 528' sampai 70 248' Lintang Selatan. Jarak terjauh dari barat ke timur sepanjang 87 $\mathrm{km}$ dan dari utara ke selatan sejauh 58 km. Secara administrasi Kabupaten Blora terletak di ujung paling timur Provinsi Jawa Tengah yang berbatasan dengan Kabupaten Bojonegoro Provinsi Jawa Timur (BPS Kabupaten Blora, 2018b).

Kabupaten Blora dengan luas 182.058,798 hektar terdiri atas lahan sawah seluas 45.948,191 hektar $(25,23 \%)$, dan sisanya lahan bukan sawah sebesar $74,77 \%$ yang terdiri atas $49,66 \%$ hutan, $14,38 \%$ tegalan, dan 10,73\% lahan untuk peruntukan lainnya.

Selama tahun 2017, rata-rata curah hujan di Kabupaten Blora tercatat sebesar $1.818 \mathrm{~mm}$ dengan rata-rata hari hujan sebanyak 113 hari dalam setahun, Hari hujan terbanyak tercatat pada bulan November dan paling sedikit pada bulan Agustus. Sedangkan untuk curah hujan tertinggi tercatat pada bulan Januari yaitu sebesar $285 \mathrm{~mm}$ dan terendah pada bulan Agustus sebesar $2 \mathrm{~mm}$. 
Jumlah penduduk Kabupaten Blora tahun 2017 tercatat sebanyak 858.865 jiwa, angka ini meningkat dibanding angka tahun 2016 yang berjumlah 855.573 jiwa. Laju pertumbuhan penduduk tahun 2017 tercatat sebesar 0,38 persen. Dengan penduduk yang terus meningkat, pada tahun 2017 mencatat tingkat kepadatan penduduk tercatat meningkat menjadi sebesar 472 jiwa/km2.

Sektor pertanian merupakan penggerak utama perekonomian sekaligus sumber utama mata pencaharian masyarakat di Kabupaten Blora. Ketersediaan air masih menjadi kendala utama sektor pertanian.

Komoditi utama berupa padi dan jagung. Komoditi jagung yang merupakan palawija andalan di Kabupaten Blora mengalami penurunan produksi sekitar 2,86 ribu ton atau turun sebesar minus 0,84\%, demikian juga dengan produksi ubi kayu turun minus 13,84\%. Sedangkan produksi kacang tanah meningkat 55,27\%; kacang hijau dan ubi jalar masing-masing mengalami peningkatan sebesar $1,12 \%$ dan $21,89 \%$.

Produktivitas tanaman padi dan palawija masih perlu terus ditingkatkan. Pada tahun 2017, produktivitas ubi kayu (339,10 kw/ha) yang jauh lebih tinggi jika dibandingkan dengan produktivitas tanaman padi sebesar $61,18 \mathrm{kw} / \mathrm{ha}$, dan palawija lainnya. Sedangkan tanaman yang mempunyai produktivitas terendah adalah kacang hijau (9,73 kw/ha).

\section{Location Quotient (LQ)}

Pembangunan suatu daerah dilakukan dengan mengidentifikasi berbagai permasalahan dan sumbersumber potensialnya sehingga memudahkan dalam penyusunan rencana secara komprehensif dan semakin mudah dalam menetapkan sasaran-sasaran yang ingin dicapai (Priana, 2016). Pertumbuhan ekonomi suatu daerah akan sangat bermakna bila pertumbuhan tersebut terjadi pada sektor yang memiliki potensi dalam mendorong proses peningkatan dan percepatan pengembangan dan pembangunan ekonomi yang termasuk dalam sektor basis (Emilia dkk, 2014).

LQ mengukur konsentrasi relatif atau derajat spesialisasi kegiatan ekonomi melalui pendekatan perbandingan (Ardhana dan Qirom, 2017). Analisis LQ menghasilkan komoditas yang tergolong dalam komoditas basis maupun non basis yang dapat berkontribusi pada peningkatan pendapatan daerah (Harinta dkk, 2018). 
Rustiadi dkk (2011) dalam Wiratama dkk (2018) menyatakan bahwa dalam suatu daerah, sektor ekonomi dibagi menjadi 2 (dua) sektor, yaitu sektor basis dan non basis dimana perbedaannya terletak pada kelebihan dan kekurangan dalam proses pemenuhan kebutuhan yang menyebabkan terjadinya mekanisme ekspor dan impor antar wilayah. Arifien dkk (2012) menyatakan bahwa komoditas basis dan komoditas non basis dapat digunakan sebagai acuan untuk mengetahui produksi pertanian suatu wilayah. Komoditas basis merupakan hasil kegiatan masyarakat yang hasilnya ditujukan ke wilayah luar, sementara komoditas non basis merupakan hasil kegiatan yang ditujukan untuk wilayah sendiri.

Pengembangan potensi unggulan daerah diharapkan dapat meningkatkan produktivitas ekonomi daerah. Investasi yang dilakukan pada potensi unggulan tersebut dapat memberikan multiplier effect yang tinggi terhadap perekonomian daerah (Rustiadi, et al, 2009 dalam Sari, 2018). Hasil analisis komoditas potensial tanaman palawija di Kabupaten Blora Provinsi Jawa Tengah disajikan pada Tabel 1.

Tabel 1. Nilai Location Quotient Komoditas Tanaman Palawija di Kabupaten Blora

\begin{tabular}{rlcccccc}
\hline \multirow{2}{*}{ No } & \multirow{2}{*}{ Kecamatan } & \multicolumn{5}{c}{ LQ } \\
\cline { 3 - 7 } & Jagung & Kedelai & Kacang tanah & Kacang hijau & Ubi jalar & Ubi kayu \\
\hline 1 & Jati & 1,0 & 3,5 & 0,0 & 1,5 & 0,0 & 0,5 \\
2 & Randublatung & 1,1 & 0,4 & 0,2 & 0,2 & 1,0 & 0,5 \\
3 & Kradenan & 1,1 & 0,2 & 0,1 & 0,0 & 1,7 & 1,3 \\
4 & Kedungtuban & 0,9 & 4,9 & 1,3 & 0,2 & 0,0 & 0,7 \\
5 & Cepu & 0,7 & 0,7 & 4,8 & 14,9 & 0,0 & 0,2 \\
6 & Sambong & 1,1 & 0,0 & 0,1 & 1,1 & 1,1 & 1,2 \\
7 & Jiken & 1,1 & 0,0 & 0,0 & 0,3 & 0,0 & 1,2 \\
8 & Bogorejo & 1,1 & 0,4 & 0,2 & 0,3 & 0,0 & 0,7 \\
9 & Jepon & 1,1 & 0,0 & 0,2 & 0,2 & 0,9 & 0,5 \\
10 & Kota Blora & 1,1 & 0,5 & 0,6 & 0,3 & 2,3 & 0,4 \\
11 & Banjarejo & 1,1 & 0,3 & 0,2 & 0,1 & 0,0 & 1,1 \\
12 & Tunjungan & 1,1 & 0,1 & 0,4 & 0,3 & 3,8 & 0,7 \\
13 & Japah & 0,8 & 2,2 & 1,7 & 2,5 & 0,0 & 4,7 \\
14 & Ngawen & 1,0 & 0,8 & 0,3 & 3,9 & 3,2 & 2,5 \\
15 & Kunduran & 0,9 & 4,2 & 0,0 & 7,3 & 1,0 & 0,5 \\
16 & Todanan & 0,9 & 0,7 & 5,6 & 0,3 & 0,0 & 0,9 \\
\hline
\end{tabular}

Tabel 1 menunjukkan potensi tanaman palawija pada kecamatan yang ada di Kabupaten Blora Provinsi Jawa
Tengah. Tanaman palawija yang ada meliputi tanaman jagung, kedelai, kacang 
tanah, kacang hijau, ubi jalar dan ubi kayu.

Tabel 1 menunjukkan bahwa tanaman jagung merupakan komoditas basis untuk Kecamatan Randublatung, Kradenan, Sambong, Jiken, Bogorejo, Jepon, Banjarejo, dan Tunjungan serta Kota Blora. Produksi jagung di wilayah tersebut melebihi kebutuhan sehingga dapat diekspor ke daerah lain.

Produksi jagung di Kecamatan Jati dan Ngawen hanya dapat digunakan untuk memenuhi kebutuhan pada kedua daerah tersebut.

Kecamatan Kedungtuban, Cepu, Japah, Kunduran dan Todanan harus membeli jagung dari luar daerah untuk memenuhi kebutuhan jagung di wilayah tersebut. Dengan kata lain, komoditas jagung merupakan komoditas non basis untuk wilayah tersebut.

Tabel 1 menunjukkan bahwa tanaman kedelai merupakan komoditas basis untuk Kecamatan Jati, Kedungtuban, Japah dan Kunduran. Produksi kedelai di wilayah tersebut melebihi kebutuhan sehingga dapat diekspor ke daerah lain.

Kecamatan Randublatung, Kradenan, Cepu, Sambong, Jiken, Bogorejo, Jepon, Banjarejo, Tunjungan, Ngawen dan Todanan, serta Kota Blora harus membeli kedelai dari luar daerah untuk memenuhi kebutuhan kedelai di wilayah tersebut. Dengan kata lain, komoditas kedelai merupakan komoditas non basis untuk wilayah tersebut.

Tabel 1 menunjukkan bahwa tanaman kacang tanah merupakan komoditas basis untuk Kecamatan Kedungtuban, Cepu, Japah dan Todanan. Produksi kacang kedelai di wilayah tersebut melebihi kebutuhan sehingga dapat diekspor ke daerah lain.

Kecamatan Jati, Randublatung, Kradenan, Sambong, Jiken, Bogorejo, Jepon, Banjarejo, Tunjungan, Ngawen dan Kunduran, serta Kota Blora harus membeli kacang tanah dari luar daerah untuk memenuhi kebutuhan kacang tanah di wilayah tersebut. Dengan kata lain, komoditas kacang tanah merupakan komoditas non basis untuk wilayah tersebut.

Tabel 1 menunjukkan bahwa tanaman kacang hijau merupakan komoditas basis untuk Kecamatan Jati, Cepu, Sambong, Japah, Ngawen dan Kunduran. Produksi kacang hijau di wilayah tersebut melebihi kebutuhan sehingga dapat diekspor ke daerah lain.

Kecamatan Randublatung, Kradenan, Kedungtuban, Sambong, Jiken, Bogorejo, Jepon, Banjarejo, 
Tunjungan dan Todanan, serta Kota Blora harus membeli kacang hijau dari luar daerah untuk memenuhi kebutuhan kacang hijau di wilayah tersebut. Dengan kata lain, komoditas kacang hijau merupakan komoditas non basis untuk wilayah tersebut.

Tabel 1 menunjukkan bahwa tanaman ubi jalar merupakan komoditas basis untuk Kecamatan Kradenan, Sambong, Tunjungan dan Ngawen, serta Kota Blora. Produksi ubi jalar di wilayah tersebut melebihi kebutuhan sehingga dapat diekspor ke daerah lain.

Produksi ubi jalar di Kecamatan Randublatung dan Kunduran hanya dapat digunakan untuk memenuhi kebutuhan pada kedua daerah tersebut.

Kecamatan Jati, Kedungtuban, Cepu, Jiken, Bogorejo, Jepon, Banjarejo, Japah dan Todanan harus membeli ubi jalar dari luar daerah untuk memenuhi kebutuhan ubi jalar di wilayah tersebut. Dengan kata lain, komoditas ubi jalar merupakan komoditas non basis untuk wilayah tersebut.

Tabel 1 menunjukkan bahwa tanaman ubi kayu merupakan komoditas basis untuk Kecamatan Kradenan, Sambong, Jiken, Banjarejo, Japah dan Ngawen. Produksi ubi kayu di wilayah tersebut melebihi kebutuhan sehingga dapat diekspor ke daerah lain.

Kecamatan Jati, Randublatung, Kradenan, Kedungtuban, Cepu, Bogorejo, Jepon, Banjarejo, Tunjungan, Kunduran dan Todanan, serta Kota Blora harus membeli ubi kayu dari luar daerah untuk memenuhi kebutuhan ubi kayu di wilayah tersebut. Dengan kata lain, komoditas ubi kayu merupakan komoditas non basis untuk wilayah tersebut.

\section{KESIMPULAN DAN SARAN}

Jagung merupakan komoditas basis untuk Kecamatan Randublatung, Kradenan, Sambong, Jiken, Bogorejo, Jepon, Banjarejo, dan Tunjungan serta Kota Blora. Kedelai merupakan komoditas basis untuk Kecamatan Jati, Kedungtuban, Japah dan Kunduran. Kacang tanah merupakan komoditas basis untuk Kecamatan Kedungtuban, Cepu, Japah dan Todanan. Kacang hijau merupakan komoditas basis untuk Kecamatan Jati, Cepu, Sambong, Japah, Ngawen dan Kunduran. Ubi jalar merupakan komoditas basis untuk Kecamatan Kradenan, Sambong, Tunjungan dan Ngawen, serta Kota Blora. Ubi kayu merupakan komoditas basis untuk Kecamatan Kradenan, 
Sambong, Jiken, Banjarejo, Japah dan

\section{DAFTAR PUSTAKA}

Amalia, F. 2012. Penentuan Sektor Unggulan Perekonomian Wilayah Kabupaten Bone Bolango Dengan Pendekatan Sektor Pembentuk PDRB. Jurnal Etikonomi 11(2): 196-207.

Ardhana, A. dan Qirom, M.A. 2017. Analisis Komoditas Unggulan di Wilayah Kesatuan

Arifien, M., Fafurida dan Noeken, V. 2012. Perencanaan Pembangunan Berbasis Pertanian Tanaman Pangan Dalam Upaya Penaggulangan Masalah Kemiskinan. Jurnal Ekonomi Pembangunan 13(2): 288-302.

Astasari, C.P., Ibrahim, J.T. dan Harpowo. 2018. Analisis Location Quotient Komoditas Cabai di Kabupaten Kediri. Journal of Agricultural Socioeconomics and Business 01(02): 11-22.

Badan Pusat Statistik Kabupaten Blora. 2018a. Blora dalam Angka 2018. Blora.

. 2018b. Statistik Daerah Kabupaten Blora 2018. Blora.

Bafadal, A. 2014. Analisis Sektor Basis Pertanian Untuk Pengembangan Ekonomi Daerah. AGRIPLUS 24(02): 152-160.

Baransano, M.A., Putri, E.I.K., Achzani, N.A. dan Kolopaking, L. 2016. Peranan Sektor Unggulan sebagai Salah Satu Faktor dalam Mengurangi Ketimpangan Pembangunan Wilayah di Provinsi Papua Barat. Jurnal Perencanaan Wilayah dan Kota (Journal of Regional and City Planning) 27(2): 119-136.

Basuki, B. dan Mujiraharjo, F.N. 2017. Analisis Sektor Unggulan Kabupaten Sleman dengan Metode
Ngawen.

Shift Share dan Location Quotient. Jurnal Sains, Teknologi dan Industri 15(1): 52-60.

Bendavid-Val, Avrom. 1991. Regional and Local Economics Analysis for Practitioners. New York: Greenwood Publishing Group, Inc.

Drianti, A. dan Ardiyanto. 2016. Analisis Location Quotient Subsektor Pertanian Unggulan Kecamatan di Kabupaten Kutai Kartanegara. Magrobis Journal 16(2): 38-47.

Emilia, Syaifuddin dan Nurjanah, R. 2014. Analisis Tipologi Pertumbuhan Sektor Ekonomi Basis dan Non Basis dalam Perekonomian Propinsi Jambi. Jurnal Paradigma Ekonomika 9(2): 1-8.

Harinta, Y.W., Basuki, JS. dan Sukaryani, S. 2018. Pemetaan dan Pengembangan Agribisnis Komoditas Unggulan Sayuran di Kabupaten Karanganyar. Jurnal Sosial Ekonomi dan Kebijakan Pertanian 7(1): 37-45.

Hidayat, E., Sutandi, A. dan Tjahjono, B. 2014. Kajian Wilayah Pengembangan Industri Kecil Berbasis Komoditas Unggulan Pertanian di Kabupaten Majalengka. Majalah Ilmiah Globë 16(2): 101-108.

Isyanto, A.Y., Sudrajat dan Sujaya, D.H, 2018. Pembangunan Ekonomi Wilayah Kabupaten Ciamis Berbasis Komoditas Peternakan. Mimbar Agribisnis 4(2): 109-120. http://dx.doi.org/10.25157/ma.v4i2. 899.

Jumiyanti, K.R. 2018. Analisis Location Quotient dalam Penentuan Sektor Basis dan Non Basis di Kabupaten 
Gorontalo. Gorontalo Development Review 1(1): 29-43.

Kharisma, B. dan Hadiyanto, F. 2017. Penentuan Potensi Sektor Unggulan dan Potensial di Provinsi Maluku. Jurnal Ekonomi \& Studi Pembangunan 19(1): 21-34.

Khasanah, N. 2018. Komoditas Tanaman Pangan dan Ternak Unggulan di Kabupaten Banyumas. Jurnal Pertanian Agros 20(2): 74-78.

Kurniawan, B. 2016. Analisis Sektor Ekonomi Unggulan Kabupaten Kerinci Provinsi Jambi. Jurnal Ekonomi Islam (Islamic Economics Journal) 4(1): 1-26.

Mahdalena, M., Simanjuntak, P. dan Nopeline, N. 2015. Analisis Sektor Basis dan Potensi Ekonomi di Kabupaten Deli Serdang. Jurnal Ekonomi dan Bisnis Nommensen VI(Januari 2015): 16-24.

Mangilaleng, E.J., Rotinsulu, D. dan Rompas, W. 2015. Analisis Sektor Unggulan Kabupaten Minahasa Selatan. Jurnal Berkala Ilmiah Efisiensi 15(4): 193-205.

Massiseng, A.N.A. dan Ummung, A. 2018. Analisis Sektor Unggulan Berdasarkan Potensi Wilayah di Kabupaten Bantaeng Sulawesi Selatan. Jurnal Ilmu Perikanan OCTOPUS 7(1): 709-717.

Munandar, T.A., Azhari, Musdholifah, A. dan Arsyad, L. 2017. Modified Agglomerative Clustering with Location Quotient for Identification of Regional Potential Sector. Journal of Theoretical and Applied Information Technology 95(5): 1191-1199.

Pengelolaan Hutan Lindung Model Hulu Sungai Selatan. Jurnal Penelitian Sosial dan Ekonomi Kehutanan 14(2): 143-155.

Priana, W. 2016. Economic Growth Model Location Quotient (LQ) in
East Java Province. JIEP 16(1): 2937.

Rakhmad, H. 2013. Analisis Komoditas Unggulan Sub Sektor Perkebunan di Kabupaten Bengkayang Provinsi Kalimantan Barat. Jurnal Social Economic of Agriculture 2(1): 5466.

Raqib, M. and Rofiuddin, M. 2018. Determination of Leading Sector Sukoharjo Regency: Location Quotient and Shift Share Esteban Marquillas Approach. International Journal of Economics, Business and Accounting Research (IJEBAR) 2(2): 107-118.

Ridwan, M., Kasmi, M. dan Putri, A.R.S. 2018. Penentuan Komoditas Unggulan Perikanan Laut Kabupaten Polewali Mandar Berdasarkan Data Statistik Tahun 2016. Jurnal IPTEKS PSP 5(10): 98-105.

Rizani, A. 2017. Analisis Potensi Ekonomi di Sektor dan Subsektor Pertanian, Kehutanan dan Perikanan Kabupaten Jember. Jurnal Ekonomi Pembangunan 15(2): 137-156.

Sapriadi dan Hasbiullah. 2015. Analisis Penentuan Sektor Unggulan Perekonomian Kabupaten Bulukumba. Iqtisaduna 1(1): 7186.

Sari, S.R. 2018. Kontribusi Sektor Pertanian dalam Struktur Ekonomi di Kabupaten Kaur Provinsi Bengkulu. AGRISEP 17(2): 175186.

Sihombing, F.N. 2018. Identifikasi Pangan Unggulan di Kota Medan: Location Quotient dan Dynamic Location Quotient. Jurnal Pembangunan Perkotaan 6(2): 9194.

Sihombing, F.N. 2018. Identifikasi Pangan Unggulan di Kota Medan: Location Quotient dan Dynamic 
Location Quotient. Jurnal Pembangunan Perkotaan 6(2): 9194.

Soleh, A. dan Maryoni, H.S. 2017. Analisis Sektor Ekonomi Unggulan dan Hubungannya dengan Kesempatan Kerja dan Investasi di Kabupaten Batanghari. Jurnal EKONOMI-Qu 7(1): 15-30.

Syafruddin, R.F., Sari, D.P. dan Kadir, M. 2018. Penentuan Komoditas
Unggulan dan Struktur Komoditas Hortikultura di Kecamatan Tinggimoncong Kabupaten Gowa Berdasarkan Location Quotient (LQ) dan Klassen Typology (KT). Jurnal Galung Tropika 7(1): 22-32. Wiratama, S., Diartho, H.C. dan Prianto, F.W. 2018. Analisis Pembangunan Wilayah Tertinggal di Provinsi Jawa Timur. e-Journal Ekonomi Bisnis dan Akuntansi V(1): 16-20. 